\title{
George TUDORIE*
}

\section{So don't you lock up something / That you wanted to see fly. What story for asylum psychiatry?}

In a rather long piece which an exhibition catalog has called ,catholic propaganda”(Busch \& Maisak, 2013, p. 342), Guido Görres reflected on madness and art, using Kaulbach's iconic 1835 drawing of asylum inmates (Das Narrenhaus) as pretext. Görres wrote of "this hospital of the human spirit (...), this charnel ground of the living, who like specters roam, wearing on their foreheads the faded and almost illegible traces of their former names." $(1836$, p. 9). Overdramatic prose, but unlikely to strike one as unprecedented. If anything, it has long been customary to exhibit a mix of fascination and revulsion when discussing the institutions which in the past two centuries at the same time sheltered and shattered those deemed mentally ill.

Kaulbach's work circulated widely via engraving, and was celebrated as an illuminating depiction of madness in its post-Pinelian career in the "reformed" asylums (Gilman, 2014, pp. 138-139). The artist was showing madness without chains, in the open, a result of its medicalization and conceptual relocation as an object of moral treatment ${ }^{2}-$ a systematic clean-up of circumstances. He was also echoing the prominence of diagnostic types, this, too, a trace of an era of hawkish alienists confident in the nosological and therapeutic powers of their discipline. The characters Kaulbach depicted remained nonetheless a mix of cultural and psychiatric typologies (Busch, 1992), of motif and symptom. They allowed, after all, his friend Görres to see a fitting image for an era of moral decay.

Not only were there readings which went beyond the medical possible, Kaulbach himself included a commentary about asylums in the work, in the form of a brutish guard overlooking the mad, baton at hand, and an almost indiscernible pair of stick figures drawn in the background by a barred window ${ }^{3}$ - a guard beating or at least threatening an inmate with a club raised over his head (see Gilman, 2014). So much for enlightened treatment! The characters may have not been chained, not even the paradigmatic raving maniac; they performed their characteristic symptoms, and presented their symbols, apparently at their discretion. But the bars were there, and so was the billy club. Ambivalence bordering on skepticism enters the picture, it would seem, with the subject of the asylum itself. Indeed, in these regions, doubts have cast shadows that became longer and more entangled still, reverberating long after the demise of asylum psychiatry.

\footnotetext{
* National University of Political Studies and Public Administration, george.tudorie@comunicare.ro
} 
In the same year Kaulbach was presenting his drawing to the public, James Cowles Prichard, psychiatrist and Quaker (Shorter, 2005, p. 227), came back to, and described in detail, a condition he called "moral insanity" (1835). Those affected had apparently intact intellectual powers, but their conduct, habits, and emotions deviated grossly from the norms of their communities. Prichard had been inspired by the work of French alienists - he discusses Pinel's manie sans délire ${ }^{4}$ - but had a level of imprecision and moralistic undertones which were his own. The morally insane were not in any case typical bedlamites - delusion was an exclusion criterion for this diagnosis (1835, pp. 21-22) - and that raised awkward juridicomedical questions. For example, of such a patient, Prichard remarks regretfully:

He was examined by several physicians, who were unanimous in the opinion that he was a lunatic; but a jury considered him to be of sound understanding, attributing his peculiarities to eccentricity, and he was consequently set at liberty. (1835, p. 44)

With a similar story, and its corresponding insanity - idiosyncrasy puzzle, begins Cristina Hanganu-Bresch and the late Carol Berkenkotter's Diagnosing Madness: The Discursive Construction of the Psychiatric Patient, 1850-1920 (2019). In 1847, Morgan Hinchman, a farmer from a Quaker community, was forcefully committed to his Pennsylvania community's Friends Hospital (aka Frankford Asylum), his peculiarities and alleged financial recklessness having passed the pale for his family and friends. After a nationally publicized trial in 1849, Hinchman regained his freedom, the moral insanity diagnosis which had been the basis for his commitment effectively annulled in court. This case of a (problematic?) medical judgment questioned and defeated in a tribunal of common law, common sense, and public opinion is indeed an ideal object of investigation for the kind of project that Hanganu-Bresch and Berkenkotter present in their book.

The volume consists of a series of vignettes drawn from the authors' archive work on $19^{\text {th }}$ and early $20^{\text {th }}$ asylum patients in the Anglophone world, and the textual footprints of their struggles against what they saw as abusive confinement. Given that a significant part of the volume is based on already published work ${ }^{5}$, with its own local focus, the book is a highly selective album rather than a tour d'horizon. The gallery it does show is however bracketed by comments on the larger significance of both its characters and its approach. The latter, unsurprisingly, covers an admittedly "heterogeneous" methodology (Hanganu-Bresch \& Berkenkotter, 2019, pp. xii, 131), loosely placed "under the umbrella of rhetoric" (2019, p. xii). I will have, at least initially, less to say about it, focusing instead on the cases themselves and on the problems related to diagnosis, the nature of illness, and the use of testimony that these patient stories raise.

The key merit, I think, of the kaleidoscopic arrangement of the book is that it allows for a level of reconstructive detail and learned contextualization which brings long dead people - and fictional characters in long dead genres - into vivid focus. The opening case, again, is well-suited for such a treatment. The Hinchman trial had significant scholarly and public echoes in its era, but it is by now largely forgotten. We are not in any case anywhere near the canonical - think Schreber ${ }^{6}$ and florid psychosis - and this makes not only for interesting storytelling, but also for an ambiguous and ramifying conceptual territory. The meanders of a $19^{\text {th }}$ century American life in a conservative community reach the walls of the asylum - despite the protagonist claiming "I am not deranged; and am deeply sensible of my many infirmities" (p. 23) - which brings up the issues of diagnosis and confinement, and the larger one of the nature of asylum psychiatry. There is then the trial, which radiates beyond the court 
and its jurisprudence, and into hearsay and newspaper battles - such "notorious cases", the authors remind us, "were usually judged twice, in court and in public opinion" (p. 17). "[T]he lines between eccentricity and madness" (p. 24) remain unclear - as they always do - but the view one has of the pieces of the puzzle is eye-opening.

In a sense, being left with the puzzle would have been perhaps the better treatment of the matter, however unsatisfying. But the substantive claims the book makes are also instructive. Some, I think, are more convincing. For example, the brief incursion in the history of the diagnosis of moral insanity makes a strong case for skepticism about this being a usable medical concept. Its juridical employment, despite the efforts and affectations of psychiatrists like Isaac Ray, raised a permanent threat of catastrophic decisions. The authors point out that public worries about such decisions were often related not only to the specter of confinement, but to sacrosanct property rights and to the moral veins crisscrossing them (e.g. wholesome entitlement vs. greed). Any picture which left such elements of context out would certainly be incomplete - and histories of psychiatry often do.

Another example is the analysis of the 1868 Davis - Ray clash in The Atlantic. Berkenkotter and Hanganu-Bresch show how issues like those at play in the Hinchman trial continued to stir public opinion and to bring into question the authority of psychiatrists as medical men with a say in judicial matters. The fact that an eminent expert went as far as to defend the scientific credentials of his profession from exposés in the popular press is indeed proof of trouble. Why is it that psychiatry needs to insist, then and now, that mental illness is illness simpliciter: "the usages of society and the common feelings of men indicate no difference between insanity and other diseases" (Ray, 1868, p. 228)? The very fact that this is a revenant of sorts in our culture is worth reflecting upon, and the book provides ample opportunity for such reflection. But it is also worth keeping in mind that such questions often act as elusive objects of fascination which tend to reflect the dissecting devices thrown at them rather than reveal their presumed insides.

A source of the critical account the authors present is what they call, later in the book, their "biases rooted in [their] humanist sensibilities"(Hanganu-Bresch \& Berkenkotter, 2019, p. 157, endnote 13). This, I suspect, I intermittently share, and a project of placing and unpacking the tense periphery surrounding diagnosis, asylum confinement, and the ensuing legal battles in a rhetorical frame would be hard to imagine in its absence. This is a view from somewhere, nonetheless, and as such it has blind spots. Leaving aside for the moment the observation that "the "moral insanity" diagnosis muddied the waters" (p. 34), the treatment of the Hinchman case in the book suggests something more damning about asylum psychiatry: an unjustified epistemic and nosological optimism resulting in therapeutic bankruptcy and brutal social control in the form of involuntary confinement. There are reasons to resist this suggestion.

Fragile as asylum psychiatry might have been in terms of its nosology or the touted benefits of moral treatment, its sinister image is problematic - the asylum is not only a legitimate, but also an easy target for retrospective criticism. And it does not seem enough that the authors gesture in the direction of the humanistic ideology which at least originally was part of the founding of asylums. Be that as it may, the diagnosis of moral insanity does not seem the best measure for what asylum psychiatry was and did, the issue of confinement here included. Paradigmatic madness, as the authors do note, remained psychotic insanity, and clearly asylum doctors had little at their disposal to deal with it. Was it because they were detached from the march of progress in true - i.e. non-psychiatric - medicine? Because they had become "petty autocrats over (...) miniature kingdoms of the mad", as Andrew Scull puts it 
(2009, p. 63)? One should perhaps consider that to our own lights the great 'de-confinement' which followed the attacks on psychiatry in the late 1960s left us with chronic homeless and prison populations plagued by mental illness. And that, for example, in one of the more consequential medical advances of the era, it was only in May 1847 (the year of Hinchman's confinement) that Semmelweis asked doctors in his Vienna obstetric clinic to wash their hands. Asylums failed, but this is a failure which should, I think, be seen in more charitable terms. This is a background issue, but it extends to the other chapters of the book as well.

At the core of the Hinchman chapter is a reading of the texts generated by the case with a particular set of tools borrowed from rhetorical theory - essentially the distinction between normal and norm, and the corresponding one between persuading and convincing introduced by Perelman and Olbrechts-Tyteca. The latter pair of notions - norm and convincing - are the stronger ones, in a hierarchy defined by the inclusiveness of one's (potential) audience. Hanganu-Bresch and Berkenkotter apply these concepts both to documents directly related to the trial, and to more distant clashes, such as that between Davis and Ray. This results in claims such as: "In the Hinchman trial, the universal norm of the right to private property overrode "normal" social behavior, which was much more narrowly defined for either Quakers or psychiatrists."(2019, p. 28). Placed, as it is, in the context of historical work, this perspective provides considerable theoretical opportunities. It allows, for example, for a mapping of the tensions between a particular scientific establishment, the legal profession, and their popular hinterland at the level of text production and circulation. This should complement well, and perhaps qualify, the work of the medical historian or the sociologist of science.

How far this incursion can penetrate into psychiatric diagnoses and their (past) manufacturing is an open question. Moral insanity makes for a good case, because it was definitive of the diagnosis that the patients were articulate. With Hinchman, for example, it seems hard to doubt that what he produced is text, and not merely symptoms. When the authors declare, at the beginning of the book, that "mental disease is a matter of public negotiation much more than a matter of scientific and medical knowledge"(2019, p. 4), they position their account against a conceptual family which includes medicalization and the Jaspersian idea that at least psychotic symptoms are mute - uninterpretable even when masquerading as discourse. Patients talk for themselves, and against their confinement, sometimes publicly (e.g. by writing petitions and memoirs). Psychiatry talks back. Rhetorical analysis can thus begin to have traction.

The difficulty here is that the distinction between text and symptom is unstable ${ }^{7}$. It should be clear that I am not making a case against there being a point to the analysis in the book. I am however pointing out that it rests on undetermined - indeed, undeterminable - presuppositions. Take the 'trope' of wrongful confinement which is manifest in Hinchman's defense. What if one wanted to apply the same reading to a case of canonical madness? Should one also think that something approaching argumentation is at work in Schreber's diatribes (1903) against his tormentor - the "little" doctor Flechsig (kleiner Flechsig) - amid rambling pages on divine rays (Strahlen) and soul-voluptuousness (Seelenwollust)? And if not, why not - is his book simply too bizarre? What about the extraordinary three volumes produced by Alexis-Vincent-Charles Berbiguier, in which, while tortured by colorful demons called "farfadets", he found the strength to demonize the doctors he consulted - among them none other than the exécrable, affreux, and infâme Pinel, "representative of Satan" (1821)? These were not eccentric rhetors, even if they published readable material, and it would do little good to treat what they said simply as discourse, or their illness as a matter of "public negotiation". 
The picture of Hinchman the book presents is far from anything so alien (as expected, given his diagnosis). However, while one does not feel the normative net of meaning coming apart - as with the elaborate psychoses exemplified above - one can neither eliminate a residue of ambiguity. The suggestions of "actual delusions" one of Hinchman's examiners made (Hanganu-Bresch \& Berkenkotter, 2019, p. 22) are inconsequential here. What matters is his unmooring from the norms of justifiable behavior - primarily in the eyes of his community, as the book argues, but even more generally (decent behavior with one's mother or basic financial prudence are rather universal - not in any case Quaker monopolies). The authors suggest that "it is possible that Hinchman appeared so clearly "insane" to his family and close friends because his behavior was so decidedly "un-Quaker"(2019, p. 23). My point is simply that, given such deviations, there is no further fact of the matter which would decide - especially retrospectively - that this was a sane man in an insane place, a position from which he produced his defense. To borrow the pair of terms used by the contemporary Boston Monthly Law Reporter, one is left, I think, with a focus which keeps switching between "depravity and disease" $(2019$, p. 29). To something like this psychiatry keeps returning with notions like folie raisonnate, moral insanity, or more recently psychopathy ${ }^{8}$.

Current debates about the medicalization ${ }^{9}$ of persistent sadness, or, on the other hand, the hidden (by stigma) epidemic of mental illness, should help the reader grasp how uncomfortable this point of view is. It presents one with a naked element of arbitrariness in our normative practices. What one does with it is a moral rather than epistemic decision. In this sense, the authors are certainly right to invoke in the context of their discussion of moral insanity the Foucauldian point that such diagnoses open the possibility of almost all behaviors becoming the object of psychiatric dissection $(2019$, p. 27) - even if in practice this possibility remains remote. One would like to err in the opposite direction.

I should stress that there is no such ambiguity when Hanganu-Bresch and Berkenkotter apply the normal-norm distinction to the Davis-Ray debate. The "fabricated" and "idealized" (2019, p. 30) image of Hinchman used by Rebecca and Clarke Davis to consolidate their own crusader credentials is set against Isaac Ray's ex cathedra dismissal of Clarke's criticism and instigation of moral panic. The opposing parties are engaged in strategic maneuvering, and it is illuminating to picture them with an eye to the audiences and sets of norms which they may have taken as decisive for their success.

The rhetorical approach comes even more into its own, somewhat paradoxically given the book's main intent, in the second chapter, which discusses two fictional representations of confinement from the 1860s-1870s, Charles Reade's Hard Cash and Rebecca Harding-Davis's Put Out of the Way. The tool of choice here is the notion of rhetorical situation, which provides a metric of discursive pressures for social change. Thus analyzed, both "novelets" have at their core an exigence - a key component of a rhetorical situation - i.e. they demand a solution for the scandal of asylum confinement based on the 'pseudo-expertise' of psychiatrists. Hanganu-Bresch and Berkenkotter show how the two writers exploited "social anxieties surrounding insanity diagnoses and familial inheritance mechanisms" (2019, p. 43), suggesting, with other voices of their time, that the rich were the likely victims ${ }^{10}$. It was not worth the effort to abusively lock up someone not in possession of an estate. Patrimonial and legal worries consequently took precedence, and the scientific status of psychiatry became a secondary issue, since the answer was suggested to be rather clear. It was becoming de rigueur for the Victorian readership of these texts to doubt that asylum psychiatry had much to do with treatment or medical science. 
An important suggestion resulting from the rhetorical situation analysis is that such works of fiction not only capitalized on an existing readership, but generated "an audience that was becoming increasingly skeptical of medical sciences, and in particular of psychiatric science" (2019, p. 40). The perspective this opens to contemporary culture wars is valuable, but this is not a road the book takes, given the chronology it is set in. The project would have been compatible, however, with a more robust take on the flimsiness of the moral high ground claimed by Reade and Davis. In other words, we are returned to the issue of calibrating one's skepticism about asylum psychiatry, ethical worries here included. Reade was denouncing psychiatric medicine as a danger for the eccentric well-off in the same year (1863) that Lincoln was setting in motion the end of slavery in the US.

In terms of exporting methods, the third chapter is, I think, less convincing ${ }^{11}$. The archival study of admission records at Ticehurst Asylum in England is a solid piece of scholarly work, but it does not seem to me that the application of speech act theoretical concepts to such documents is providing critical insight. What the authors do, for example, in reconstructing Henrietta Unwin's story and in showing that "flouting the conventions of Victorian womanhood"(Hanganu-Bresch \& Berkenkotter, 2019, p. 71) could lead to the use of labels such as "nymphomaniac" is more to the point and completes their overall assessment of moral insanity. This is in no way dependent on a mapping of illocutionary forces in commitment documents, even if obviously the documents did carry said forces.

An echo of the previous chapter is the discussion of an insidious form of abuse which is always threatening when one becomes a patient, especially a mental patient. It may be inherent, to put it in fashionable terms, to the medical 'gaze'. For example, discussing their second case, Hanganu-Bresch and Berkenkotter point out that "Marshall found that much of what he said and did was interpreted as evidence of his intractability and hence of his insanity" (2019, p. 76). This, too, is a trope in critical histories of medicine - any form of resistance to medicalization becoming itself a symptom which justifies medicalization. What the patient says ${ }^{12}$ is immediately bracketed, as if he or she tried to move in a frictionless fish tank. While I think this captures something both tragic and unavoidable in the real world, one should keep in mind the difficulties I discussed in the Hinchman case. Bizarre behavior already destabilizes discourse. While undoubtedly important, medical prejudice or the clinician's power as observer and taxonomist should not be made into hyperbolic evils in such contexts.

More than once in the book, characters form bridges between chapters that are different in tone, focus, or scope. This is the case with the Davises in the first two chapters, and with Walter Marshall in the third and fourth. The latter chapter brings up in even clearer terms the crucial issue I mentioned above: the status of personal narratives or autobiographical stories deploring diagnosis and condemning confinement. If Marshall testified in 1877 for the Select Commission on Lunacy Law, arguing that in his case mundane ills had been taken for symptoms of insanity - and reasons for asylum confinement, the second former patient, Charles Merivale, produced an extended and more interesting written denunciation, in the form of a memoir.

My Experiences in a Lunatic Asylum (Merivale, 1879) is a mesmerizing text, as it is often the case with such testimonies. Hanganu-Bresch and Berkenkotter suggest that we read it as counter-narrative, and that concepts such as "emplotment" and narrative causality can help one see how it works as such. Thus, Merivale is not simply listing a series of events what led to, and what ended his confinement, for example - he is not simply telling a story, but arranging said events into a plot. The story is told as fable, and there is a confrontation- 
al conclusion to it. He is ready to admit he was not well, but confinement worsens his condition. Doctors play decisive roles in the sequence of events, but they are superficial and confused about the nature of his problems. Moreover, the segments of the story are not arranged in a simple chronology - in "metronomic time" - but "symphonically" (Hanganu-Bresch \& Berkenkotter, 2019, p. 85), with numerous digressions and literary apropos.

I particularly appreciate the subtlety of the analysis here, and, as in other occasions, the decisive role of detailed contextualization (e.g. the discussion of Merivale's other published works and of his curious biographical omissions). The authors are spot on, I think, when they ask "how much narrative control did Merivale actually exert when he wrote his memoir?" and remark that "[t]here is no way to answer this question" (2019, p. 96). I am less confident than they are that one can bypass this question and let, as it were, the text speak for itself, given that it does echo recognizable genres and tropes (it is an exposé of wrongful confinement). But it is not that I would argue that one can simply note the merits of not answering an unanswerable question.

Merivale is not confronting imaginary farfadets, but a medico-legal machinery which often enough produced ethical and therapeutic disasters. Early in his memoir, he is dismissive of powerful doctors "who know what Galen knew and no more, but apparently believe in themselves none the less"(1879, pp. 23-24), and sets up the resistance-as-symptom argument in particularly clear terms. "I could not afford to be angry", he remarks sarcastically, "for that would have been 'excitement' and madder still." $(1879$, p. 34). But it seems to me unmistakable that after a point the irony, sarcasm, or trivialization of own troubles (e.g. he had 'fancies', not 'delusions') take a life of their own, hurting in fact his counter-narrative. It is as if Merivale cannot resist abusing what he possibly took to be his devastating humor. And where Hanganu-Bresch and Berkenkotter see engineered and genre-specific digressions and "outpouring of erudition" (2019, p. 96), one can also see a rather recognizable manic emptiness and verbal inflation. The merit of the book here is that it does signal these convoluted possibilities. And perhaps we should pay attention to them when thinking about the current fad of producing and consuming 'survival' stories.

In the final chapter of the book, the authors use the concept of 'enregisterment' to describe the impact of Kraepelin's nosology on British diagnostic practice. The Ticehurst archive is again the source of examples. I am not in a position to evaluate what this perspective does to a more regular historical perspective. The latter would be one in which, rather than seeing Kraepelin's systematization as a "linguistic register" (Wilce quoted in Hanganu-Bresch \& Berkenkotter, 2019, p. 104) which displaces previous diagnostic categories due to the "primacy of classification" (p. 105) for aspiring scientific communities, one looks for example at the predictive power of the Kraepelinian nosology vs. the notorious instability of categories such as moral insanity. The minimal hypothesis in this case is that doctors followed the evidence. Obviously, this is not the only thing they did.

An important observation in the chapter is that once a more mechanical and clear-cut system of diagnosis was adopted - leaving aside whether this was an instance of "nomenclature frenzy" (Hanganu-Bresch \& Berkenkotter, 2019, p. 130) - the "the patient disappeared from the notes." (p. 129). It had been a talent of those earlier alienists in the dreaded asylums to look and see - to leave "in textual amber" (p. 8), as the authors so beautifully put it at the beginning of the book, at least a semblance of the living beings under their power and care. This too, in our time of electronic 'wearables' judging our health or wellbeing, is worth reflecting upon. 
How - how fast, how deep - the particular utopia embodied in the psychiatric asylums of the $19^{\text {th }}$ century failed is by now a refrain of our culture. We have for long had rituals and processions to the ruins. And we continue to look their way, out of sheer fascination or due to our own fears of there being, in Merivale's words, "death-in-life" $(1879$, p. 3$)$ in the customs, institutions, and language of our own time. Cristina Hanganu-Bresch and Carol Berkenkotter have us see some of the bits and pieces in the atypical light of rhetorical theory, and, to the student of these regions, they have thus provided a complement to more orthodox historiographical, sociological, and even philosophical scholarship. The lay, educated reader, perhaps having seen at some point Shock Corridor (Fuller, 1963) or having made the expected stop by Kesey's novel (1963), will find in the book a more distant layer of stories, and as such an opportunity to contextualize received opinions.

If, for a moment, we looked again at Kaulbach's drawing, we could note how easy it would be to miss its import if, for example, we failed to place it in the shadow of Hogarth's earlier representation of Bedlam. There's the freak-show like spectacle of an $18^{\text {th }}$ century madhouse, and then there's the asylum, with its distinct flavor of humanism and darkness. We would miss much, perhaps, about our own affair with DSM psychiatry these days, if we did not look at the crucial period in the second half of the $19^{\text {th }}$ century in which the Enlightenment habit of natural observation and natural history turned into recognizable modern psychiatry. Diagnosing madness: The discursive construction of the psychiatric patient, 1850-1920 helps us to do just that.

\section{Notes}

${ }^{1}$ My translation.

${ }^{2}$ See also Charlie Deitz's review in this issue.

${ }^{3}$ That barred window, not unlike Fra Angelico's in the Annunciation in terms of placement, perhaps an ironic sign of an upside-down, all-innocence-lost, hortus conclusus (see Grovier, 2021).

${ }^{4}$ On the difficulties of mapping the meaning of délire, see (Berrios, 1996, pp. 93-100; 424-425).

${ }^{5}$ See (Berkenkotter \& Hanganu-Bresch, 2011) for the Unwin and Marshall cases, (Hanganu-Bresch \& Berkenkotter, 2012) for the Marshall and Merivale cases, (Hanganu-Bresch, 2014) for the Hinchman trial, and (Hanganu-Bresch, 2019) for the concept of moral insanity.

${ }^{6}$ See (Schreber, 1903) and its (in)famous analysis in (Freud, 1911).

${ }^{7}$ Not only for clear-cut psychoses. Even if no one would see moral insanity as a medical notion today, elements of it survive in current medical and medico-juridical categories. Commenting on David Jones' work, Cristina Hanganu-Bresch notes that "there is a nearly uninterrupted thread between earlier concepts of moral insanity and personality disorder/criminal insanity - for which the uniting factor is the insanity plea in criminal cases" (2019, p. 807).

${ }^{8}$ See e.g. (Crego \& Widiger, 2015) for why psychopathy as such is not part of the DSM nomenclature, and (Seabrook, 2008) for an example of debating the notion in the popular press.

${ }^{9}$ See Laura Russell's review in this issue for a discussion of medicalization which is more consistent with Hanganu-Bresch and Berkenkotter's project.

${ }^{10}$ Similarly, Andrew Scull writes about "a persistent disquiet that manifested itself in periodic spasms of anxiety" (2015, pp. 264-265).

${ }^{11}$ I might see it this way because my familiarity with the field is limited (but I remain nonetheless unconvinced that e.g. there could be a 'null hypothesis' in which commitment certificates are anything other than directives). See however Alexandru Cârlan's review in this issue for a more technical analysis.

${ }^{12}$ I refer the reader, again, to Laura Russell's review in this issue for an empathetic discussion of patient voices and the phenomenology of being seen as a mental patient. 


\section{References}

Berbiguier, A.-V. C. (1821). Les Farfadets, ou tous les démons ne sont pas de l'autre monde: Vol. I. P. Gueffier, Imprimeur.

Berkenkotter, C., \& Hanganu-Bresch, C. (2011). Occult genres and the certification of madness in a 19thcentury lunatic asylum. Written Communication, 28(2), 220-250.

Berrios, G. E. (1996). The history of mental symptoms: Descriptive psychopathology since the nineteenth century. Cambridge University Press.

Busch, W. (1992). Überlegungen zur Hogarth-Rezeption bei Chodowiecki und Kaulbach. Zeitschrift des Deutschen Vereins für Kunstwissenschaft, 46, 9-19.

Busch, W., \& Maisak, P. (2013). Verwandlung der Welt: Die romantische Arabeske. Freies Deutsches Hochstift, Frankfurter Goethe Museum.

Crego, C., \& Widiger, T. A. (2015). Psychopathy and the DSM. Journal of Personality, 83(6), 665-677. https://doi.org/10.1111/jopy.12115.

Freud, S. (1911). Psychoanalytische Bemerkungen über einen autobiographisch beschriebenen Fall von Paranoia (Dementia paranoides). In GESAMMELTE WERKE: VIII: WERKE AUS DEN JAHREN 1909-1913 (pp. 240-316). Imago Publishing.

Fuller, S. (1963, September 25). Shock Corridor [Drama, Mystery]. Allied Artists Pictures, F\&F Productions.

Gilman, S. L. (2014). Seeing the insane. A Visual and Cultural History of Our Attitudes Toward the Mentally Ill. Echo Point Books \& Media.

Görres, G. (1836). Das Narrenhaus von Wilhelm Kaulbach: Nebst Ideen über Kunst und Wahnsinn. Morgenblatt für gebildete Stände.

Grovier, K. (2021, April 1). Fra Angelico's Annunciation: Sexual clues in a barred window. https://www.bbc. com/culture/article/20210330-fra-angelicos-annunciation-sexual-clues-in-a-barred-window.

Hanganu-Bresch, C. (2014, May). Arguing psychiatric diagnoses: Mental illness and law in the 19th centu$r y$. Rhetoric Society of America, San Antonio, TX.

Hanganu-Bresch, C. (2019). Public Perceptions of Moral Insanity in the 19th Century. The Journal of Nervous and Mental Disease, 207(9), 805-814. https://doi.org/10.1097/NMD.0000000000001035.

Hanganu-Bresch, C., \& Berkenkotter, C. (2012). Narrative survival: Personal and institutional accounts of asylum confinement. Literature and medicine, 30(1), 12-41.

Hanganu-Bresch, C., \& Berkenkotter, C. (2019). Diagnosing madness: The discursive construction of the psychiatric patient, 1850-1920. University of South Carolina Press.

Kesey, K. (1963). One Flew Over the Cuckoo's Nest. Signet.

Merivale. (1879). My Experiences in a Lunatic Asylum. By a Sane Patient. Chatto and Windus, Piccadilly.

Prichard, J. C. (1835). Treatise on Insanity and Other Disorders Affecting the Mind. Sherwood, Gilbert, and Piper.

Ray, I. (1868, August). „A Modern Lettre de Cachet” Reviewed. The Atlantic, 22, 227-243.

Schreber, D. P. (1903). Denkwürdigkeiten eines Nervenkranken. Oswald Mutze. https://www.projekt-gutenberg.org/schreber/nervenkr/nervenkr.html.

Scull, A. (2009). Hysteria: The biography. Oxford University Press.

Scull, A. (2015). Madness in Civilization. A Cultural History of Insanity from the Bible to Freud, from the Madhouse to Modern Medicine. Princeton University Press.

Seabrook, J. (2008, November 10). The Minds of Psychopaths. The New Yorker. https://www.newyorker.com/ magazine/2008/11/10/suffering-souls.

Shorter, E. (2005). A historical dictionary of psychiatry. Oxford University Press. 